\title{
Research on the Plasma Anemometer Based on AC Glow Discharge
}

\author{
Bing Yu, Enyu Shen, Pei Yuan, and Huaxu Shen \\ Nanjing University of Aeronautics and Astronautics, Jiangsu Province Key Laboratory of Aerospace Power System, \\ Key Laboratory of Aero-Engine Thermal Environment and Structure, Ministry of Industry and Information Technology, \\ Nanjing 210016, China \\ Correspondence should be addressed to Bing Yu; yb203@nuaa.edu.cn
}

Received 6 December 2016; Revised 5 February 2017; Accepted 7 February 2017; Published 28 February 2017

Academic Editor: Paolo Bruschi

Copyright (C) 2017 Bing Yu et al. This is an open access article distributed under the Creative Commons Attribution License, which permits unrestricted use, distribution, and reproduction in any medium, provided the original work is properly cited.

\begin{abstract}
A new plasma anemometer based on AC glow discharge is designed in this article. Firstly, theoretical analysis of plasma anemometer working principle is introduced to prove the feasibility of the experimental measurement method. Then the experiments are carried out to study the effects of different parameters on the static discharge characteristics of the plasma anemometer system, by which the system optimization methods are obtained. Finally, several groups of appropriate parameters are selected to build the plasma anemometer system based on resistance capacitance coupling negative feedback AC glow discharge, and different airflow speeds are applied to obtain the achievable velocity measurement range. The results show that there is a linear relationship between airflow velocity and discharge current in an allowable error range, which can be applied for airflow velocity measurement. Negative feedback coupling module, which is composed of the coupling resistance and the coupling capacitance, has good effects on improving the system stability. The measurement range of the airflow velocity is significantly increased when the electrode gap is $3 \mathrm{~mm}$, coupling resistance is $470 \Omega$, and coupling capacitance is $220 \mathrm{pF}$.
\end{abstract}

\section{Introduction}

Airflow velocity measurement technology is a long-studied subject, and it has been widely applied in many fields, such as aviation, spaceflight, meteorology, and military [1]. Due to the strict requirements of the traditional anemometers for measuring environment, these anemometers cannot measure the airflow velocity accurately and even cannot work in the harsh environment. Although the rotor or cup type mechanical anemometers can measure airflow from different directions, big size and poor accuracy limit their developments [2]. Pitot tube anemometers have better accuracy for measuring high airflow velocity and are not affected by air pollution; however large size and bad accuracy for low speed measurements are main defects [3]. The piezoelectric anemometers also can measure airflow from different directions; however, the anemometers are easily affected by temperature and even fail to work in high temperature environment [4]. The above anemometers all have some limitations, so new measurement technology which can measure airflow velocity in harsh environment and meet different measurement requirements is desired. And then a plasma airflow velocity measurement method based on gas discharge emerged.

The concept of anemometer based on gas discharge can be traced back to the last century; it was firstly presented through the relationship between voltage, current, and wind speed in gas discharge test by Lindvall [5]. A German research team inspired by the work of Lindvall applied gas discharge to measure turbulence and ultimately achieved success in 1941. In the following three years, relevant experimental data was summarized well by Fucks, and some airflow velocity measurement rules based on gas discharge were obtained [6]. A low noise DC glow discharge anemometer was designed successfully by Mettler in 1949, and it was applied to measure the 1.6 Ma supersonic flow field and obtained the good effect [7]. Corona discharge was employed to measure airflow velocity by Werner and Geronime, which made good achievement in 1953 [8]. With the rapid development of electronic technology 
and the researches on gas discharge, the plasma anemometer based on glow discharge designed by Vrebalovich was continually improved by Matlis and Corke after 2003. The frequency of the discharge power supply was increased, and the voltage of the discharge power supply was decreased, which greatly reduced the power required by the glow discharge and the damage to the plate. The biggest progress is mainly in two aspects: first, the measuring probe reaching $\mu \mathrm{m}$ level through adopting MEMS (microelectromechanical system) manufacturing technology, which reduced the effect of the probe on the airflow field, and the sensor had better resolution; second, applying the constant current glow discharge system for error control and using the computer to collect discharge signal, process the data, and control current of the discharge circuit, which improved the measuring range and accuracy of system [9-16].

There are exactly many researches on discharge or plasma anemometers for decades; here, only three typical anemometers based on gas discharge are introduced as follows. In 1985, in order to observe stratospheric turbulence, [17] presented a glow-discharge ionic anemometer based on glow discharge. The anemometer has two mesh electrodes, and the third electrode is applied to collect the ions interacting with airflow. The ion collector of the anemometer is partitioned into four insulated segments. When glow discharge happens and there is no airflow, equal ion currents flow into the four segments. When the airflow appears, the ions will drift downstream and the partial currents flowing into the four segments will be different from each other. The glow discharge between mesh electrodes is stable under pressures of 10-30 Torr; therefore, the anemometer can only measure weak flows of low-pressure gases, which greatly limits its application. In 2011, [9] introduced a constant current plasma anemometer for measuring the airflow velocity from subsonic to hypersonic. By keeping the discharge current constant, the airflow velocity could be obtained by measuring discharge gap voltage. In order to keep the discharge current constant, an active closed-loop feedback controller has been added to the plasma anemometer system. Although the measuring method is advanced, the constant current control brings many difficulties and the cost improvements. In 2015, [1] presented a DC planar ionic anemometer for measuring the airflow velocity of boundarylayers near a surface; the anemometer includes two symmetrical cathodes and one anode with a sharp tip. When DC voltage is applied to electrodes, the ions will be attracted symmetrically to the two cathodes. If there is no airflow, the currents of two symmetrical cathodes are the same. When the airflow appears, the downstream electrode can receive more ions than the upstream electrode. Although the anemometer has high accuracy, the applied high DC voltage would cause great damage to the electrodes and is hard to generate stable glow discharge. Therefore, it cannot measure airflow for a long time and its measurement range of airflow velocity is limited.

The presented plasma anemometer has been improved greatly in many aspects; it can not only operate continually in standard atmospheric air but also greatly decrease the realization costs of the system. The working principle, design,

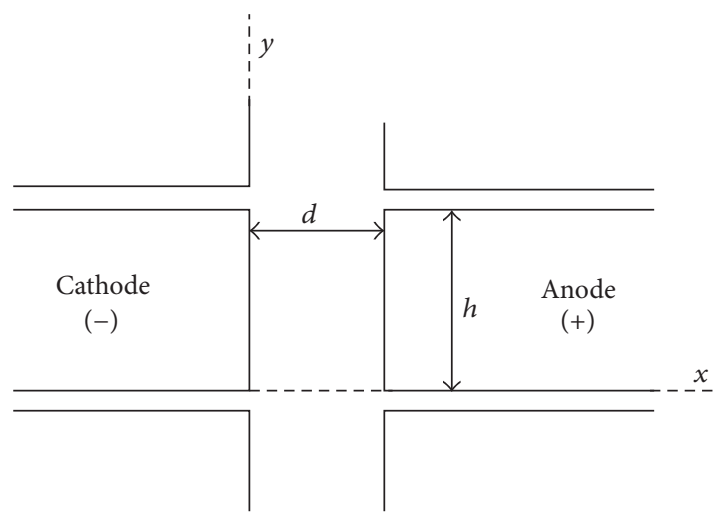

FIGURE 1: The plasma generator structure of the plasma anemometer.

parameters effects studies, and airflow measurement experiments of the presented plasma anemometer will be illustrated in the following sections.

\section{Theoretical Analysis of Plasma Anemometer Working Principle}

The theoretical analysis of DC plasma anemometer was firstly proposed by Mettler in 1949 [7], which is also applicable to AC plasma anemometer. The plasma generator structure of the plasma anemometer is shown in Figure 1, where $d$ is the electrode gap and $h$ is the electrode diameter. Between two parallel electrodes, when the gas is punctured by high AC voltage, then a relatively steady plasma region is generated. If there is no airflow, the total number of electrons leaving from $\mathrm{cm}^{2} / \mathrm{s}$ of cathode can be expressed as

$$
n_{e c}=n+\lambda n_{i}
$$

where $n$ is the constant number of electrons leaving from $\mathrm{cm}^{2} / \mathrm{s}$ of cathode, which is caused by constant power voltage, $\lambda$ is proportional constant depending on the energy of the positive ions, the field strength at the cathode, the cathode material, and the condition of cathode surface, and $n_{i}$ is the number of positive ions arriving at $\mathrm{cm}^{2} / \mathrm{s}$ of cathode

The number of new charged particles produced in any length $d x$ of plasma area per second is as follows:

$$
d n_{i}=n_{e x}(x) \alpha d x,
$$

where $n_{e x}(x)$ is the number of electrons crossing $\mathrm{cm}^{2} / \mathrm{s}$ at distance $x$ and $\alpha$ is the Townsend coefficient.

The number of electrons crossing $\mathrm{cm}^{2} / \mathrm{s}$ at a distance $x$ can be calculated by

$$
n_{e x}(x)=n_{e c} e^{a x} .
$$

The integral of (2) is

$$
n_{i}=\alpha \int_{0}^{d} n_{e x}(x) d x .
$$

Substituting (3) and (4) into (1),

$$
n_{e c}=n+\lambda \alpha \int_{0}^{d} n_{e c} e^{a x} d x
$$




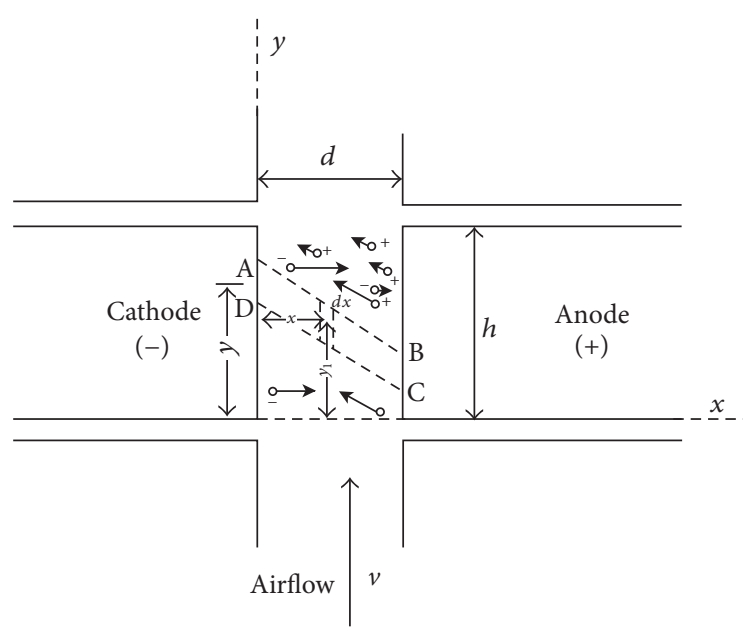

FIgURE 2: Motion diagram of charged particles under airflow.

Solving (5), $n_{e c}$ can be calculated as follows:

$$
n_{e c}=\frac{n}{1-\lambda\left(e^{\alpha d}-1\right)} \text {. }
$$

Then, $n_{e x}(x)$ can be obtained as follows:

$$
n_{e x}(x)=\frac{n e^{\alpha x}}{1-\lambda\left(e^{\alpha d}-1\right)} .
$$

When the airflow is applied to the plasma region, there is angle $\theta$ between $x$-axis and the ion motion path under the combined action of airflow and electric field. Figure 2 is motion diagram of charged particles under airflow.

$$
\theta=\tan ^{-1}\left(\frac{v}{\tau_{i} E_{x}}\right),
$$

where $v$ is the speed of airflow applied between two electrodes, $\tau_{i}$ is the mobility of the ions, $E_{x}$ is the field strength, and $\tau_{i} E_{x}$ is the velocity of positive ions in the $x$ direction.

When the airflow appears, (1) is took place by

$$
n_{e c}(y)=n+\lambda n_{i}(y) \text {. }
$$

As shown in Figure 2, electrons are still moving along $x$ axis, so the number of electrons crossing $\mathrm{cm}^{2} / \mathrm{s}$ at $\left(x, y_{1}\right)$ can be calculated by

$$
n_{e x}\left(x, y_{1}\right)=n_{e c}\left(y_{1}\right) e^{\alpha x}
$$

The total number of new ions produced in the area $\mathrm{ABCD}$ in Figure 2 is

$$
n_{i}(y)=\alpha \int_{0}^{d} n_{e c}\left(y_{1}\right) e^{\alpha x} d x .
$$

Substituting (11) into (9),

$$
n_{e c}(y)=n+\lambda \alpha \int_{0}^{d} n_{e c}\left(y_{1}\right) e^{\alpha x} d x
$$

From Figure 2, the following equations can be obtained:

$$
\begin{aligned}
x & =\frac{\tau_{i} E_{x}}{v}\left(y-y_{1}\right), \\
d x & =-\frac{\tau_{i} E_{x}}{v} d y_{1} .
\end{aligned}
$$

Substituting (13) into (12),

$$
\begin{aligned}
& n_{e c}(y) \\
& \quad=n+\frac{\lambda \alpha \tau_{i} E_{x}}{v} \int_{y-v d / \tau_{i} E_{x}}^{y} n_{e c}\left(y_{1}\right) e^{\left(\alpha \tau_{i} E_{x} / v\right)\left(y-y_{1}\right)} d y_{1} .
\end{aligned}
$$

It can be found that the total number $n_{e c}(y)$ of electrons leaving from $\mathrm{cm}^{2} / \mathrm{s}$ of cathode is correlated to airflow velocity by (14), and circuit current is also related to the number of discharged particle arriving at electrodes. Therefore, the change of airflow velocity would result in the circuit current change, which can be used as the measurement principle of plasma anemometer experiments.

When the stable glow discharge happens between two electrodes, the plasma region is mainly composed of electrons and ions. The positive and negative charges are usually equal, so the plasma region is electrically neutral. When the airflow appears, the direction of airflow is parallel to $y$ direction. Due to the fact that the mass of the electron is very small, it will obtain a very large velocity in $x$ direction under the effect of the electric field, the airflow effect on electrons moving velocity in $y$ direction can be neglected, and the electrons are still moving along $x$ direction. However, the mass of the ion is much larger than the electrons, the airflow effect on the ions in $y$ direction cannot be neglected, and some ions will escape from the plasma region under the effect of airflow. With the increase of airflow velocity, more ions would escape from the plasma region and cannot arrive at the cathode. Therefore, the velocity change of airflow would also change the circuit current value, and the airflow measuring method of the presented plasma anemometer is feasible.

\section{Design of Plasma Anemometer System}

3.1. Resistance Capacitance Coupling Negative Feedback Mechanism. The generation of the discharge plasma is a positive feedback process. When the electrode gap voltage reaches the gas breakdown voltage, the discharge occurs. Electrons frequently collide in the process of moving, that is, the electron avalanche phenomenon. The number of electrons increases rapidly, the discharge current also increases, which causes that a large number of charged particles and the heat to generate, thereby decreasing the electrode gap resistance. However, in a short period of time, the voltage is essentially kept unchanged, so with the decrease of the resistance, discharge current increases further, thereby forming a positive feedback process. The discharge becomes more intense and unstable [18].

If a suitable negative feedback mechanism can be introduced to suppress the positive feedback process, the atmospheric pressure glow discharge in air can be realized [19]. 


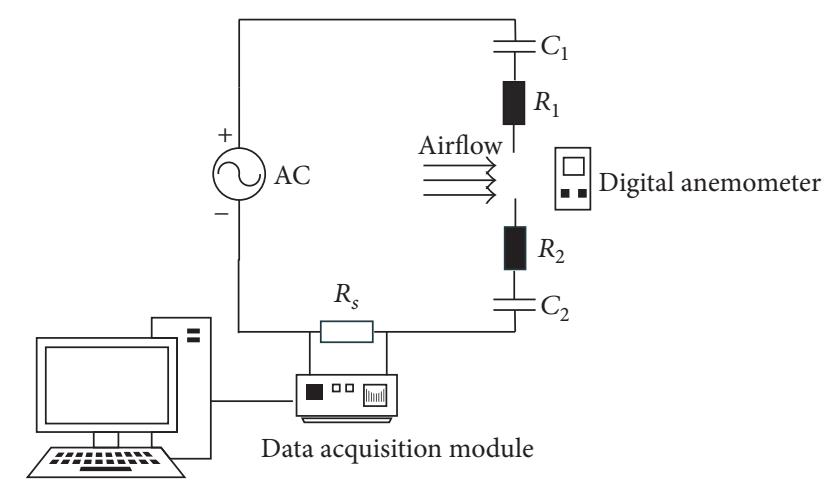

Data processing module

FIgURE 3: The structure diagram of the plasma anemometer system based on resistance capacitance coupling negative feedback AC glow discharge.

Figure 3 is the structure diagram of the plasma anemometer system based on resistance capacitance coupling negative feedback AC glow discharge. Each electrode of the system is connected with a resistance $R$ and capacitance $C$. These coupling resistances and capacitances can provide a negative function to control discharge development process effectively, thereby preventing the transition from glow discharge to spark discharge. Under the mediation of the negative feedback mechanism, the rising rate of the discharge current is effectively controlled, which avoids the occurrence of the spark discharge. In the case that the discharge condition has been determined, the discharge mode is determined by the coupling time constant $\tau=R * C, R\left(R=R_{1}+R_{2}\right)$ is the loop coupling resistance, and $C\left(C=\left(C_{1} * C_{2}\right) /\left(C_{1}+C_{2}\right)\right)$ is the loop coupling capacitance. By changing the coupling time constant, the negative feedback mechanism can be employed to realize the glow discharge in the air.

3.2. Experimental Device. The structure diagram of the plasma anemometer system based on resistance capacitance coupling negative feedback AC glow discharge is shown in Figure 3. The system is mainly composed of power module, negative feedback coupling module, plasma generator, data acquisition module, data processing module, airflow supply module, and digital anemometer. The power module adopts AC voltage source, the power supply device is CTP$2000 \mathrm{~K}$, and the output voltage of the power supply can be adjusted continuously within $0-30 \mathrm{kV}$, and discharge frequency adjustable range is within 5-20 kHz. The plasma generator is composed of two similar metal probes, the material of the probes is mainly copper, its length is about $3 \mathrm{~cm}$, and diameter is about $0.8 \mathrm{~mm}$. One probe connected with high voltage terminal of power supply device is as anode, and the other connected with low voltage terminal of power supply device is as cathode. The plasma can be generated between two electrodes when the gas discharge happens, discharge distance can be adjusted continuously within $0-5 \mathrm{~mm}$. The negative feedback coupling module composed of coupling resistance and coupling capacitance is utilized to suppress the positive feedback process of the discharge and improve the system stability. The loop coupling resistance $R=R_{1}+R_{2}$, and the loop coupling capacitance $C=\left(C_{1} * C_{2}\right) /\left(C_{1}+C_{2}\right)$, $R_{1}=R_{2}, C_{1}=C_{2}$. The data acquisition module consists of a sampling resistance, a voltage sensor, and an AD (analogto-digital) conversion circuit. Sampling resistance $R_{s}$ is $50 \Omega$, loop current is measured indirectly by measuring voltage variation on sampling resistance, and then electrical signals are converted into digital signals by the AD conversion circuit; finally, the datse transmitted from $\mathrm{AD}$ conversion circuit are processed and analyzed by data processing module. Airflow supply module is composed of air compressor, valve, and injector, which could provide adjustable airflow velocity, the range of airflow speed is about $0-150 \mathrm{~m} / \mathrm{s}$. Digital anemometer adopted in the experiment is thermal digital anemometer, its measurement range of airflow speed is within $0-30 \mathrm{~m} / \mathrm{s}$, and the accuracy of the anemometer is about $\pm 3 \%$. The relationship between airflow velocity and discharge current is calibrated by digital anemometer in atmospheric pressure environment.

\section{The Effects of System Parameters}

A stable gas discharge system must be established before carrying out the experimental study of the airflow velocity measurement. Therefore, the effects studies of different parameters on gas discharge are required to obtain the system optimization methods. The parameters effects of electrode gap, coupling capacitance, and coupling resistance on the system stability are discussed in the following sections. All tests are carried out in standard atmospheric pressure air, and all the experimental data are processed by software called Origin.

4.1. The Effect of Electrode Gap. According to the theory of gas breakdown, the breakdown voltage of the uniform electric field is a function of the product of the gas pressure $P$ and the discharge gap $d$ [20]. During the experiments, the gas pressure is standard atmospheric pressure, so the discharge gap is one of the important parameters which affect the gas discharge. The study shows that when the electrode gap is less than $1 \mathrm{~mm}$ and the gas discharge happens between two electrodes, due to the electrode gap is too small, the charged particles produced by gas discharge are continuously and easily bombarded with two electrodes under the driving of the electric field, which leads to the temperature of two electrodes raising rapidly, thereby melting the metal electrodes. However, when the electrode gap is more than $5 \mathrm{~mm}$, due to the fact that the output voltage is limited, gas cannot be punctured by limited output voltage and gas discharge is hard to generate.

In order to research the effect of electrode gap on gas discharge, the coupling resistance is $200 \mathrm{k} \Omega$, the coupling capacitance is $30 \mathrm{pF}$, and power frequency is $12 \mathrm{kHz}$. The output voltage is constant, and electrode gaps $d$ are $1 \mathrm{~mm}, 2 \mathrm{~mm}, 3 \mathrm{~mm}$, $4 \mathrm{~mm}$, and $5 \mathrm{~mm}$, respectively. The waveform of current and gap voltage for different electrode gaps is presented in Figure 4.

As shown in Figure 4, electrode gap has a great influence on the discharge current. The difference of electrode gap will affect the peak value of discharge current. The current peaks 

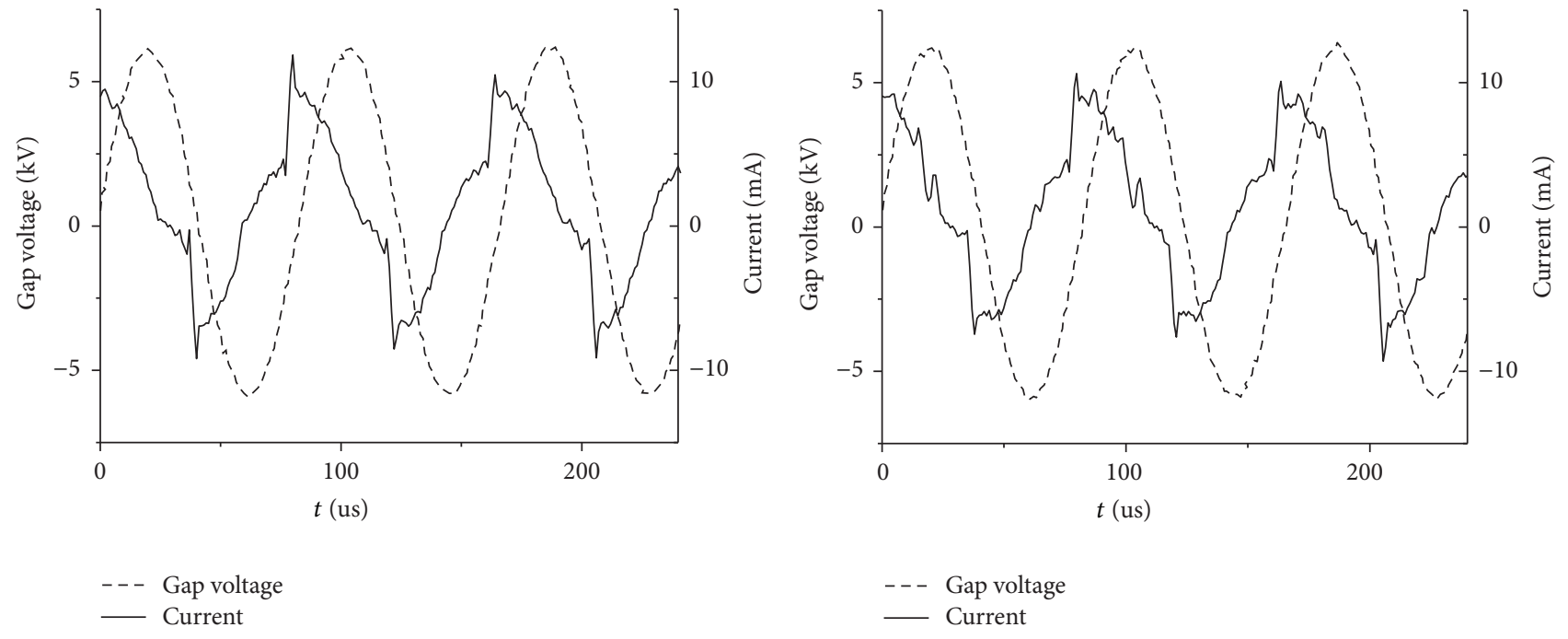

(a) Electrode gap $d=1 \mathrm{~mm}$

(b) Electrode gap $d=2 \mathrm{~mm}$
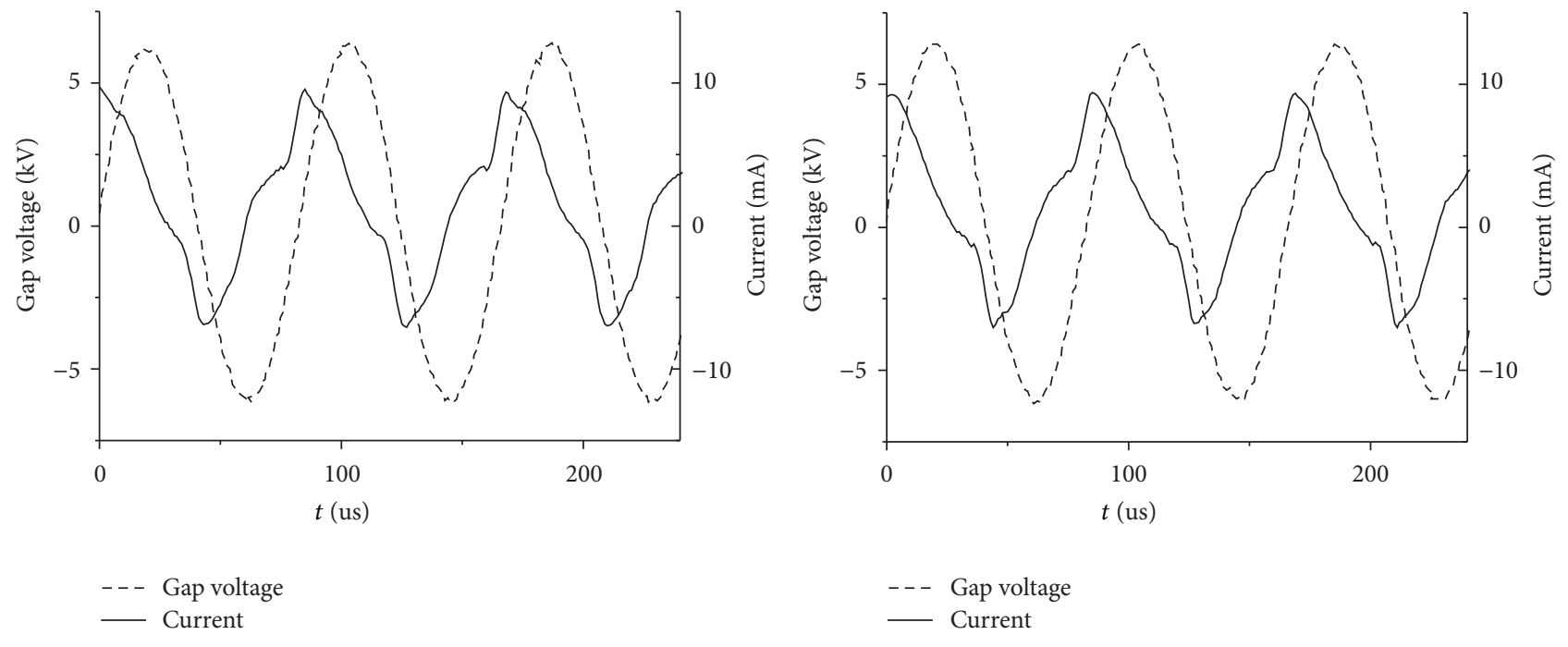

(c) Electrode gap $d=3 \mathrm{~mm}$

- - Gap voltage

Current

(d) Electrode gap $d=4 \mathrm{~mm}$

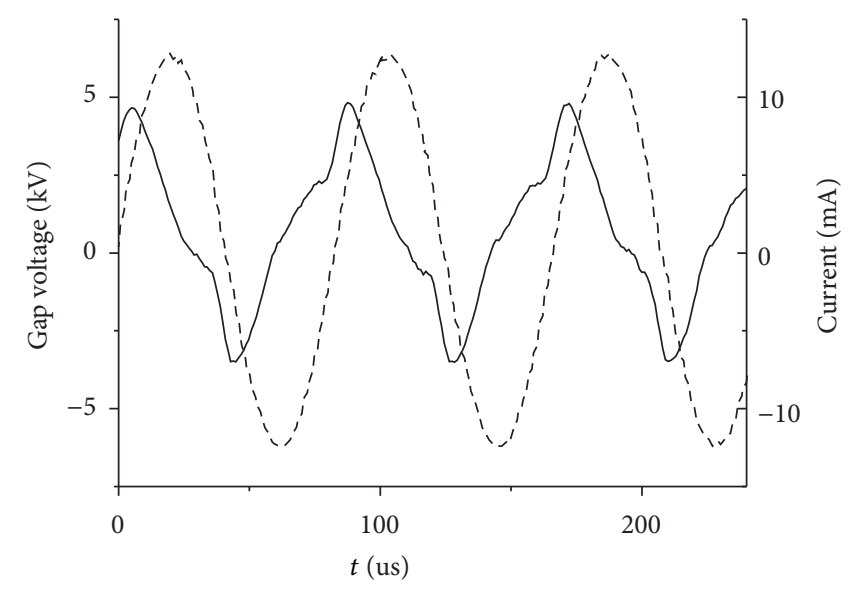

- - Gap voltage
_ Current

(e) Electrode gap $d=5 \mathrm{~mm}$

FIGURE 4: The waveform of current and gap voltage for different electrode gaps. 
of $1 \mathrm{~mm}, 2 \mathrm{~mm}, 3 \mathrm{~mm}, 4 \mathrm{~mm}$, and $5 \mathrm{~mm}$ are $12.5 \mathrm{~mA}, 11.3 \mathrm{~mA}$, 10.4 $\mathrm{mA}, 9.6 \mathrm{~mA}$, and $9.5 \mathrm{~mA}$, respectively. With the increase of the electrode gap, the peak value of discharge current decreases; however, when $d$ increases to a certain value, the discharge current changes little. This phenomenon can be interpreted as follows: on the one hand, due to the increase of electrode gap, the space electric field is weakened, the energy which electron in the unit distance obtains is reduced, and the discharge current is reduced with weakening of ionization. On the other hand, with the decrease of the discharge current, the voltage on the capacitance $C_{1}, C_{2}$ and resistance $R_{1}, R_{2}$ would decrease. When the supply voltage is constant, the electrode gap voltage increases will increase the discharge current in turn; although the discharge current is still decreasing, the decreasing rate declines. When the electrode gap is $2-5 \mathrm{~mm}$, the system can realize stable glow discharge.

4.2. The Effect of Coupling Capacitance. The process of producing plasma by gas discharge is a positive feedback process, which can cause the discharge to become more intense. Eventually, the discharge transits to arc discharge or spark discharge. In order to limit the continuous growth of discharge current, the coupling capacitance and coupling resistance are introduced to provide a negative feedback mechanism, which can prevent the transition from glow discharge to arc discharge or spark discharge, thereby realizing stable discharge.

Firstly, the effect of coupling capacitance on the gas discharge is researched. Coupling resistance is $0 \Omega$, power frequency is $12 \mathrm{kHz}$, the output voltage is constant, the electrode gap is $d=3 \mathrm{~mm}$, and the coupling capacitances are $30 \mathrm{pF}, 50 \mathrm{pF}, 100 \mathrm{pF}, 220 \mathrm{pF}$, and $470 \mathrm{pF}$, respectively. The waveform of current and gap voltage for different coupling capacitances is shown in Figure 5.

As presented in Figure 5, with the decrease of the coupling capacitance, the peak current decreases, and the gap voltage increases gradually. This phenomenon can be explained by the following circuit principle: when the power frequency is constant, the capacitance is smaller, and the capacitance impedance is greater, which causes the discharge current decreases. When the power supply voltage is constant, the gap voltage increases accordingly with the decrease of discharge current. When the coupling capacitance is reduced to $30 \mathrm{pF}$, the current waveform changes, and the pulse time of the peak value decreases sharply. This is because the introduction of the coupling capacitance affects the time constant of the circuit, and the time constant of the circuit decreases with the reduction of the coupling capacitance, which enhances the reverse electric field, and the discharge can be extinguished in a relatively short time. Furthermore, the decrease of the coupling capacitance also changes the phase of the discharge current.

4.3. The Effect of Coupling Resistance. In order to study the influence of the coupling resistance on the static discharge characteristics of the plasma anemometer system, the coupling capacitance is $0 \mathrm{pF}$, the power frequency is $12 \mathrm{kHz}$, the output voltage is constant, the electrode gap is $3 \mathrm{~mm}$, and the coupling resistances are $470 \Omega, 10 \mathrm{k} \Omega, 100 \mathrm{k} \Omega, 200 \mathrm{k} \Omega$, and $400 \mathrm{k} \Omega$, respectively. Figure 6 is the waveform of current and gap voltage for different coupling resistances.

As shown in Figure 6, with the increase of coupling resistance, discharge current amplitude decreases gradually, and the gap voltage increases gradually. This is because the greater the coupling resistance is, the greater the impedance of the circuit is, which causes the discharge current decreases. When power supply voltage is constant, the resistance voltage decreases with the decrease of current, which causes the gap voltage increases. Moreover, the coupling resistance can affect the discharge current waveform. When the coupling resistance is $470 \Omega$, current waveform is pulse type, and the waveform at the peak is not smooth and there is a sharp pulse. Sharp pulse disappears with the coupling resistance increasing, current pulse width increases gradually, and the waveform is gradually close to the sine wave. When the coupling resistance is increased to $200 \mathrm{k} \Omega$, the difference between discharge current waveform and the sine wave can be ignored.

\section{Airflow Velocity Measurement}

The experimental results of different parameters effects show that when the electrode gap is too large, it is difficult to produce gas discharge; however, the electrode gap is too small, which may cause the electrode to melt; the discharge current waveform is more close to sine wave with coupling resistance increasing; however, the coupling resistance is too large, which increases the resistance power loss; when the coupling capacitance is too large, the ability to establish the reverse electric field is weakened, and the discharge stability is weakened, which may cause the discharge transition to arc discharge.

Considering the discharge stability and the electrode safety, five different coupling resistances are selected to carry out airflow velocity measurement experiments: coupling resistances are $0 \Omega, 10 \Omega, 100 \Omega, 200 \Omega$, and $470 \Omega$, respectively, coupling capacitance is $220 \mathrm{pF}$, and the power frequency is $12 \mathrm{kHz}$. The airflow velocity measurement tests are performed in atmospheric pressure air environment.

Firstly, the experimental platform is built to realize the stable gas discharge, and then, gradually increasing airflow velocity from $0 \mathrm{~m} / \mathrm{s}$, the waveform changes of discharge current and gap voltage for different coupling resistances and airflow velocities can be observed by the data processing module. Figure 7 is the chart of airflow velocity measurement experiment, and Figure 8 is the waveform of current and gap voltage for different airflow velocities when coupling resistance is $200 \Omega$

As presented in Figure 8, the effects of airflow velocity on the current are mainly reflected in the current waveform and discharge current peak. When the airflow velocity is $0 \mathrm{~m} / \mathrm{s}$, due to the introduction of coupling capacitance and coupling resistance, the current waveform is close to sine wave. When the airflow velocity is $2.42 \mathrm{~m} / \mathrm{s}$, a pulse generates near the current peak, and the pulse width is gradually narrowed with the increase of airflow velocity. When the airflow velocity is $6.93 \mathrm{~m} / \mathrm{s}$, discharge is unstable, the current amplitude of 


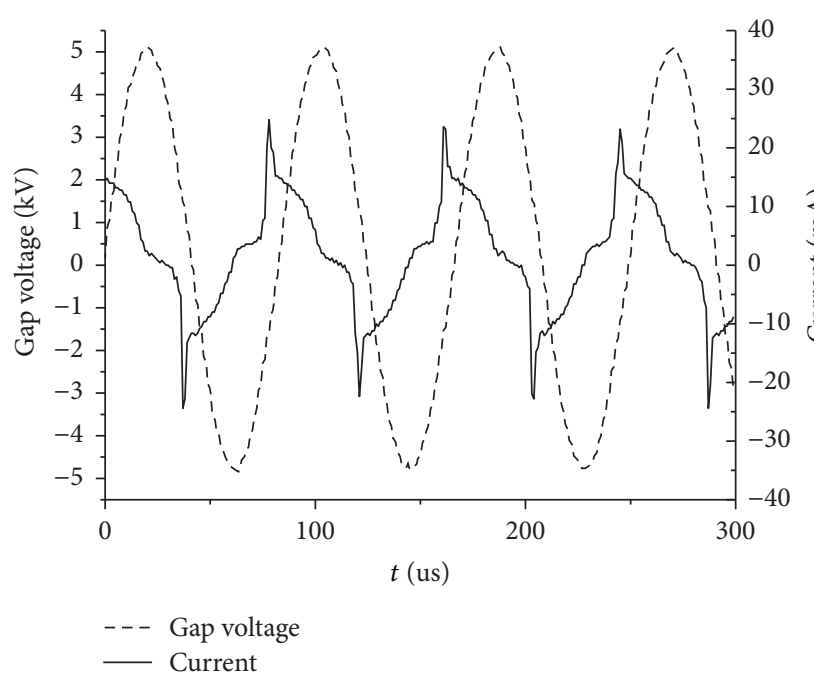

(a) Coupling capacitance is $30 \mathrm{pF}$

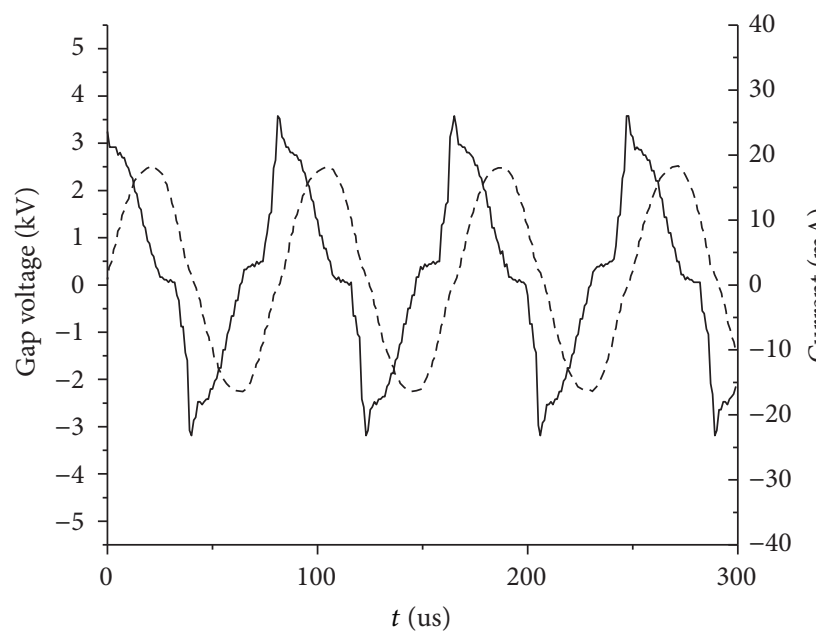

- - - Gap voltage

- Current

(c) Coupling capacitance is $100 \mathrm{pF}$

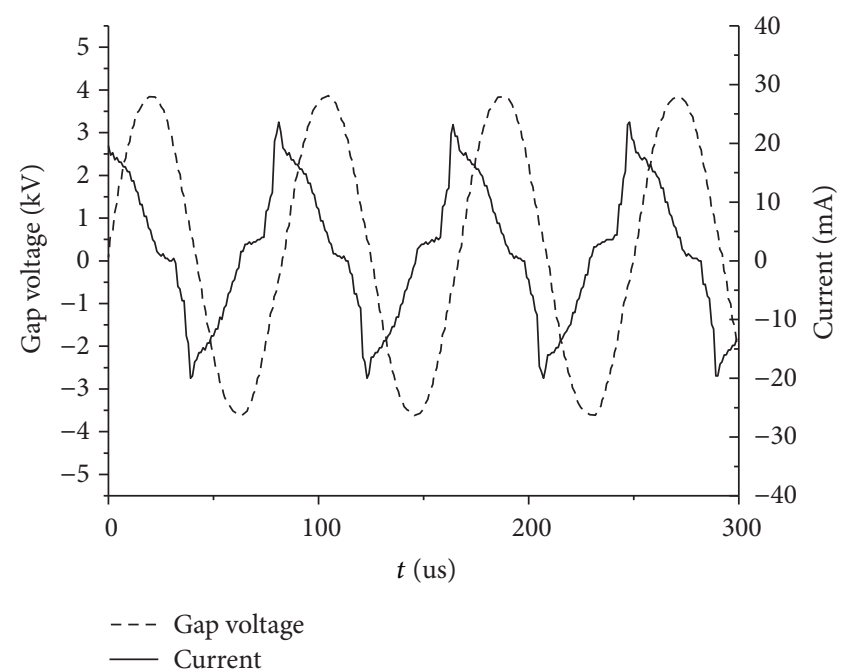

(b) Coupling capacitance is $50 \mathrm{pF}$

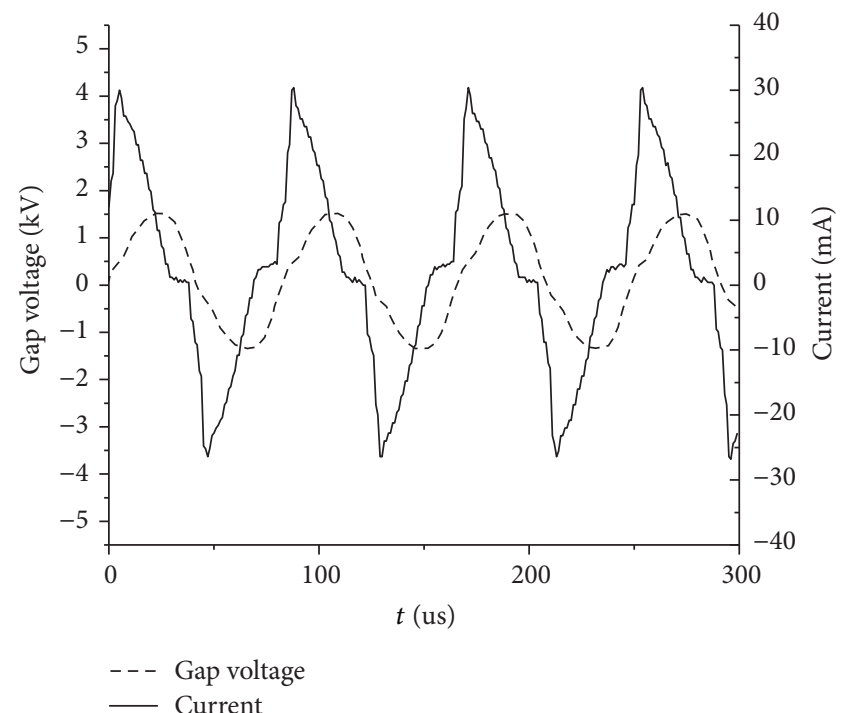

(d) Coupling capacitance is $220 \mathrm{pF}$

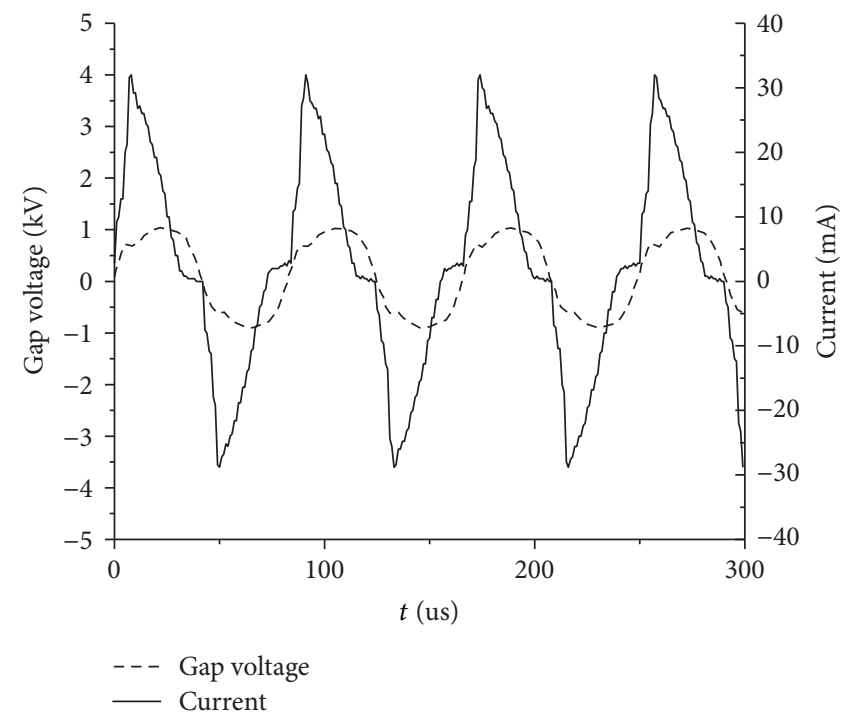

(e) Coupling capacitance is $470 \mathrm{pF}$

FIGURE 5: The waveform of current and gap voltage for different coupling capacitances. 


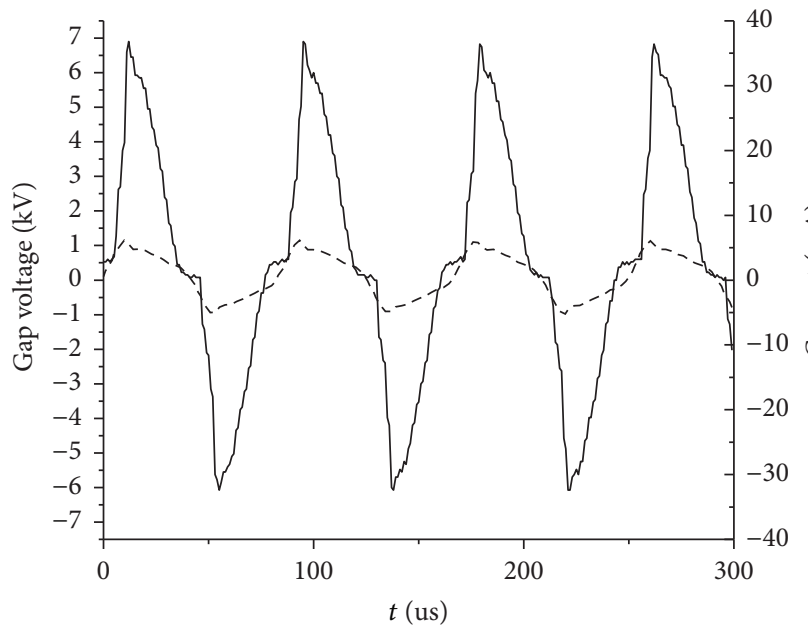

- - - Gap voltage

- Current

(a) Coupling resistance is $470 \Omega$

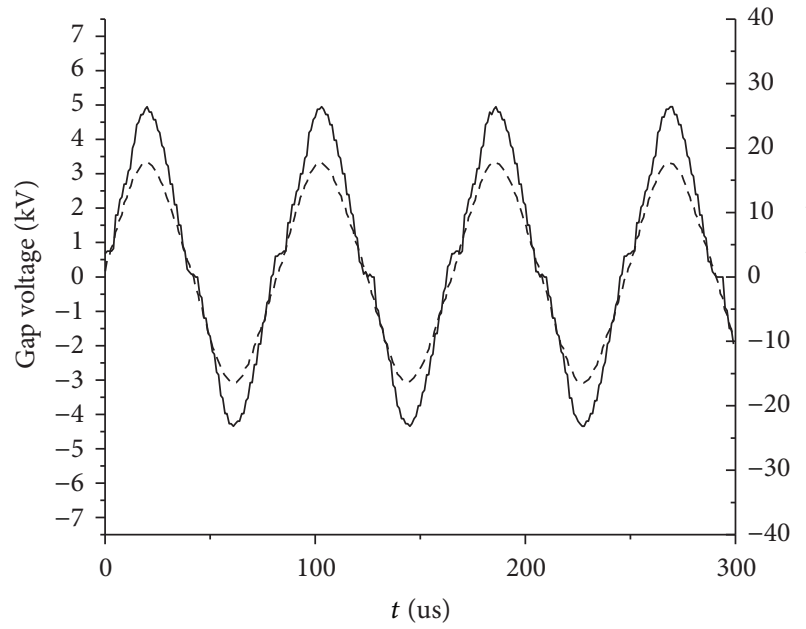

- - - Gap voltage

- Current

(c) Coupling resistance is $100 \mathrm{k} \Omega$

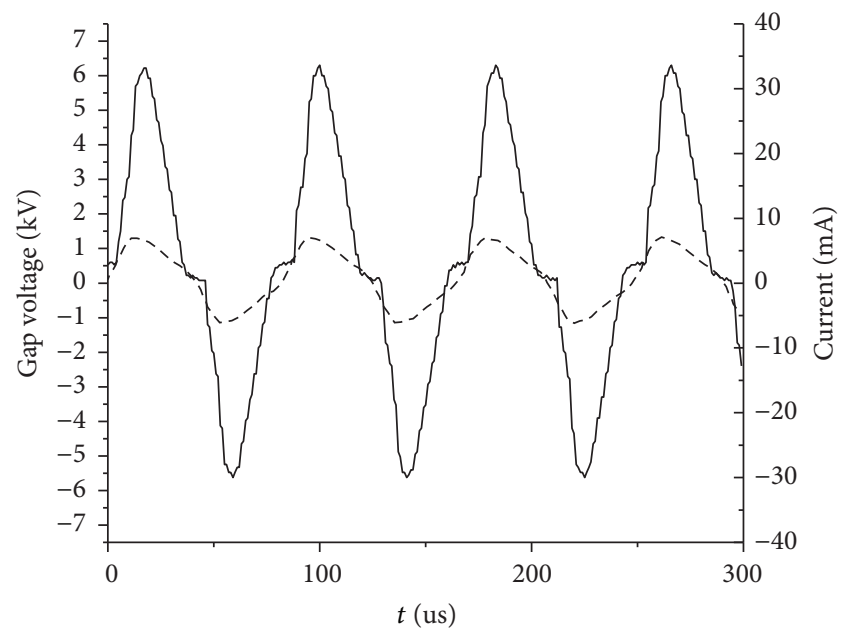

- - Gap voltage

(b) Coupling resistance is $10 \mathrm{k} \Omega$

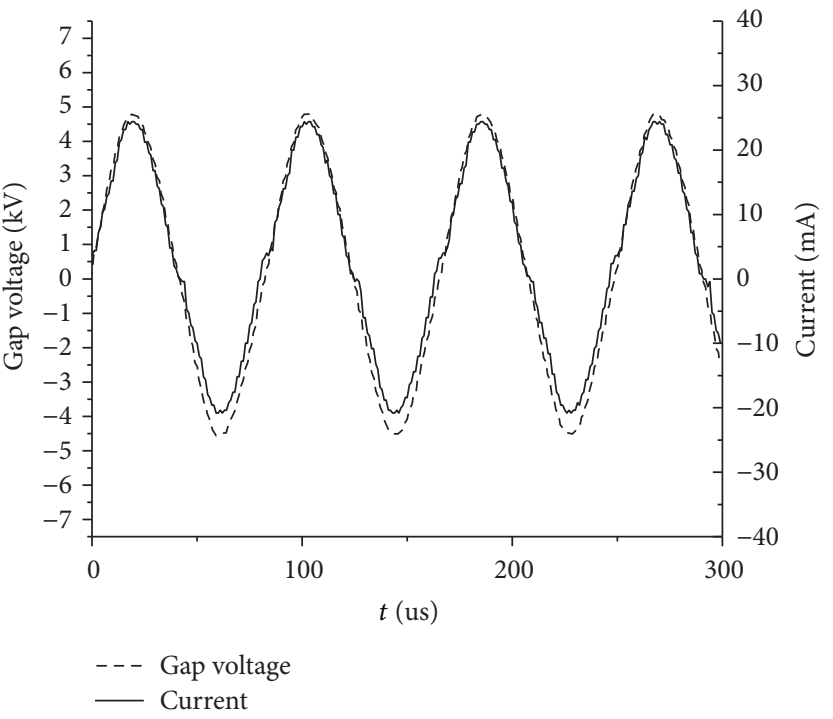

(d) Coupling resistance is $200 \mathrm{k} \Omega$

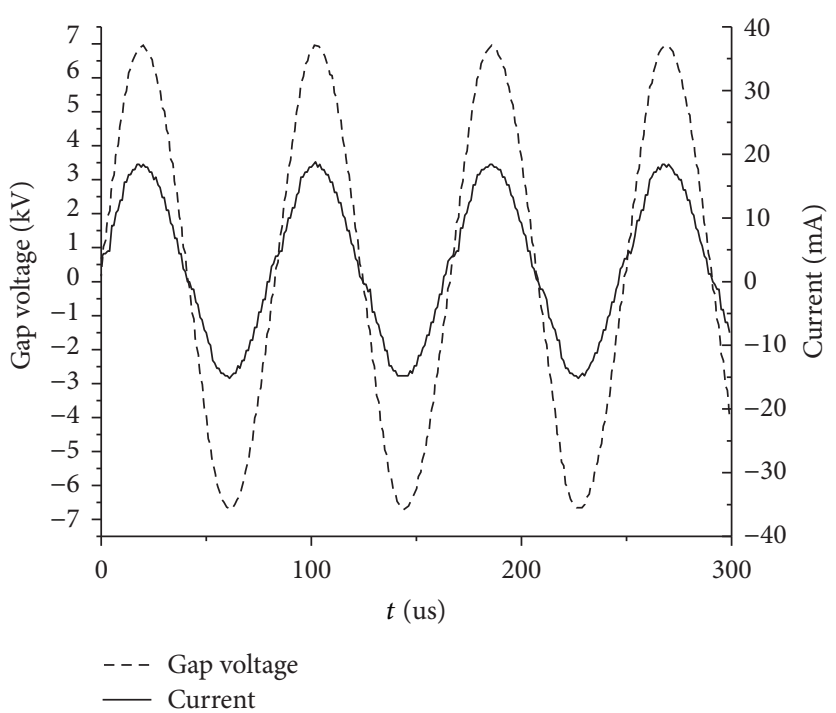

(e) Coupling resistance is $400 \mathrm{k} \Omega$

FIGURE 6: The waveform of current and gap voltage for different coupling resistances. 


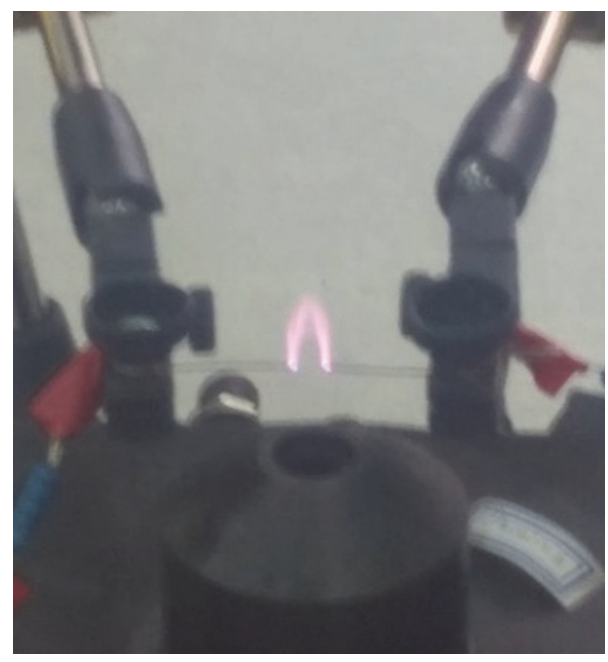

FIgURE 7: The chart of airflow velocity measurement experiment.

each cycle is different, and a small number of white filaments appear between the electrodes. When the velocity is $8.17 \mathrm{~m} / \mathrm{s}$, the current waveform is very unstable, the number of white filaments increases, and the discharge current appears a large spike pulse. The conversion of discharge mode from the glow discharge to the spark discharge causes the generation of the pulse. With the increase of airflow velocity, the number of charged particles escaping from the electrodes increases, when the power supply voltage is not enough to sustain the discharge, the discharge is extinguished.

The discharge current waveform of different airflow velocities is not a standard sine waveform, and the current pulse width of different airflow velocities is not consistent. So, the current peak value cannot be used for the calibration of the plasma anemometer. Due to the fact that the effective value of the current is the average value of the gas heating, which can better reflect the current characteristics, the effective value of the current is utilized for the calibration of the system. The effective value is also called root mean square value, so the effective value of the current can be obtained by the following equation:

$$
I_{\mathrm{rms}}=\frac{1}{50} \sqrt{\frac{\sum_{i=1}^{n} U_{i}^{2}}{n}}
$$

where $I_{\mathrm{rms}}$ is the effective value of the discharge current and $U_{i}$ is the voltage on the sampling resistance $R_{s}, R_{s}=50 \Omega$.

Figure 9 is the relationship diagram of airflow velocity and the effective value of the current.

As shown in Figure 9, the experimental results reveal that the introduction of the negative feedback coupling module improves greatly the stability of plasma anemometer system. Meanwhile, there is a linear relationship between airflow velocity and discharge current, which can be applied for airflow velocity measurement. When the electrode gap is $3 \mathrm{~mm}$, coupling resistance is $470 \Omega$ and coupling capacitance is $220 \mathrm{pF}$, the range of airflow velocity measurement has a great improvement, compared with the system without the negative feedback coupling module, and the system is optimized obviously and measurement range of airflow velocity significantly increases.

Compared to the plasma anemometers introduced in $[1$, $9,17]$, our method is a low cost, practical, and easy to realize one. Although the existing approaches mentioned above have made great success in airflow measurement, these plasma anemometers also have some limitations, which restrict their development. As reported in [1], the anemometer adopts DC voltage source, which would cause damage to electrodes and the stable glow discharge is hard to sustain. In [9], Matlis and Cork have built a constant current plasma anemometer for measuring airflow velocity of several Mach numbers, and this work might be the best one in this field; however, the active constant current control at Mega $\mathrm{Hz}$ level is very difficult and expensive. As to [17], the anemometer can only measure airflow velocity in low-pressure environment. The presented plasma anemometer adopts AC voltage source, which can realize stable glow discharge continually in standard atmospheric air. And the airflow velocity can be obtained by measuring discharge current; the passive control method of presented measuring system is greatly stable, reliable, and easy to realize. After equipping a negative feedback coupling module, the stability of the system has been improved greatly, which makes the measuring range of the presented plasma anemometer higher than the plasma anemometers presented in $[1,17]$. Therefore, the presented plasma anemometer has a more widely applicable prospect and deserves to make deeper researches.

\section{Conclusions}

In the article, theoretical analysis of plasma anemometer operational principle is introduced to prove the feasibility of experiments. And then the effects of different system parameters are studied. The experimental results show that there is a linear relationship between airflow velocity and discharge current in an allowable error range, which can be applied for airflow velocity measurement; after the appropriate parameters are selected, the system is optimized obviously; with the introduction of negative feedback coupling module, the stability and measurement range of the system have a great improvement.

\section{Competing Interests}

The authors declare no conflict of interests.

\section{Authors' Contributions}

B. Yu first proposed the idea of this research and finished the theoretical analysis. B. Yu, E. Shen, P. Yuan, and H. Shen carried out the experiments. P. Yuan, E. Shen, and H. Shen processed and analyzed the experiments data. B. Yu and E. Shen finished the manuscript writing. 


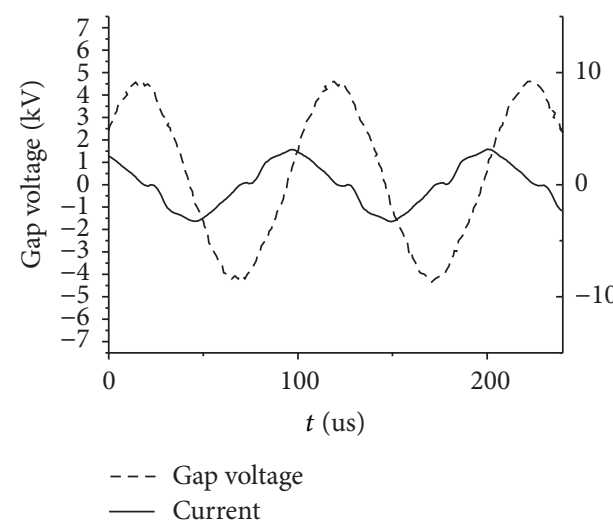

(a) $V=0 \mathrm{~m} / \mathrm{s}$

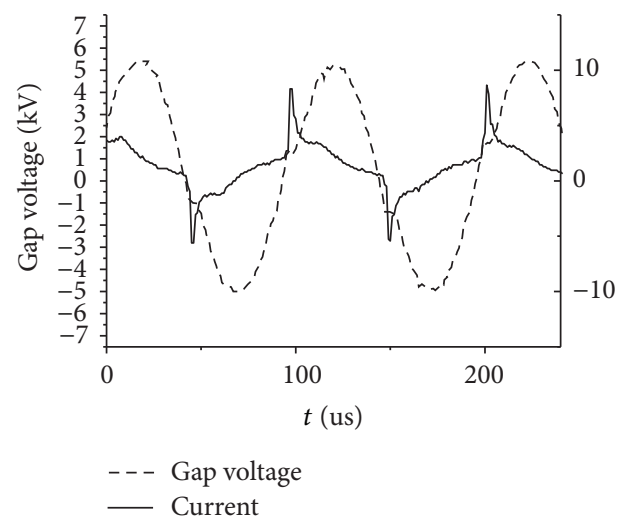

(c) $V=3.39 \mathrm{~m} / \mathrm{s}$

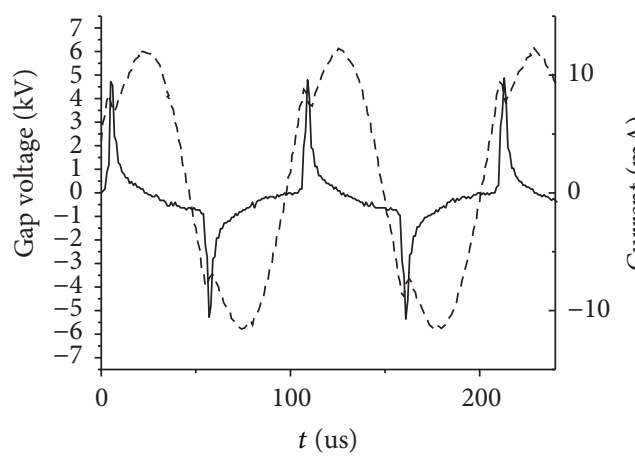

- - Gap voltage
_ Current

(e) $V=5.56 \mathrm{~m} / \mathrm{s}$

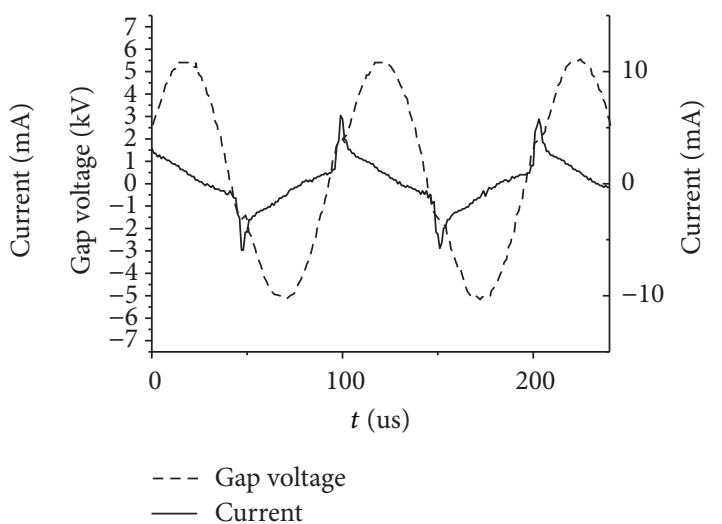

(b) $V=2.42 \mathrm{~m} / \mathrm{s}$

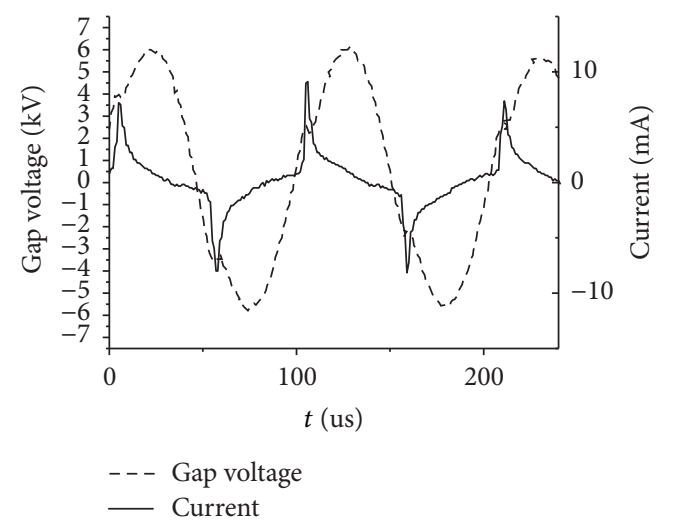

(d) $V=4.48 \mathrm{~m} / \mathrm{s}$

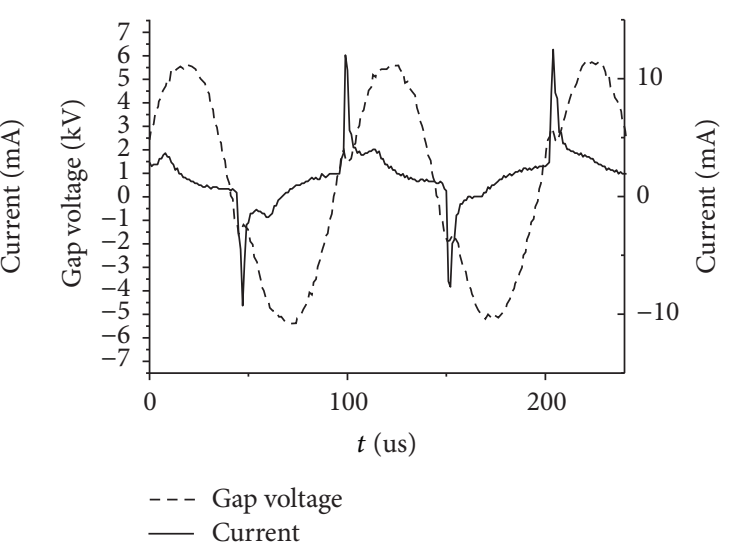

(f) $V=6.93 \mathrm{~m} / \mathrm{s}$

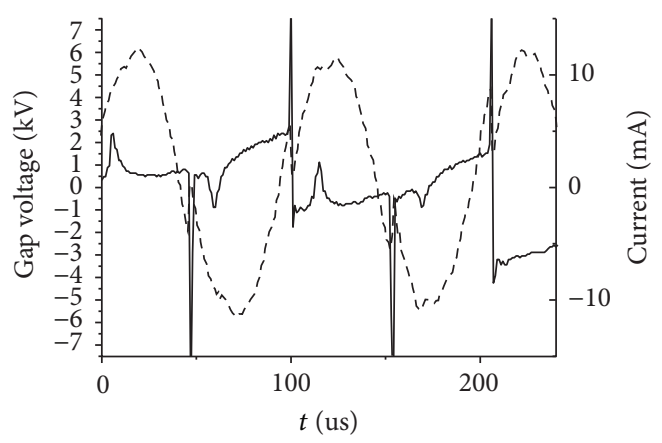

- - - Gap voltage

- Current

(g) $V=8.17 \mathrm{~m} / \mathrm{s}$

FIGURE 8: The waveform of current and gap voltage for different airflow velocities when the coupling resistance is $200 \Omega$. 


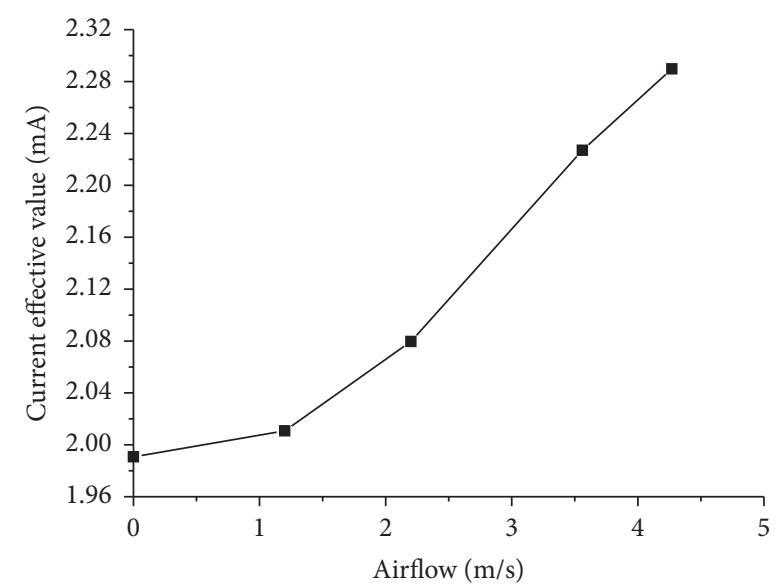

-- Current effective value

(a) Coupling resistance is $0 \Omega$

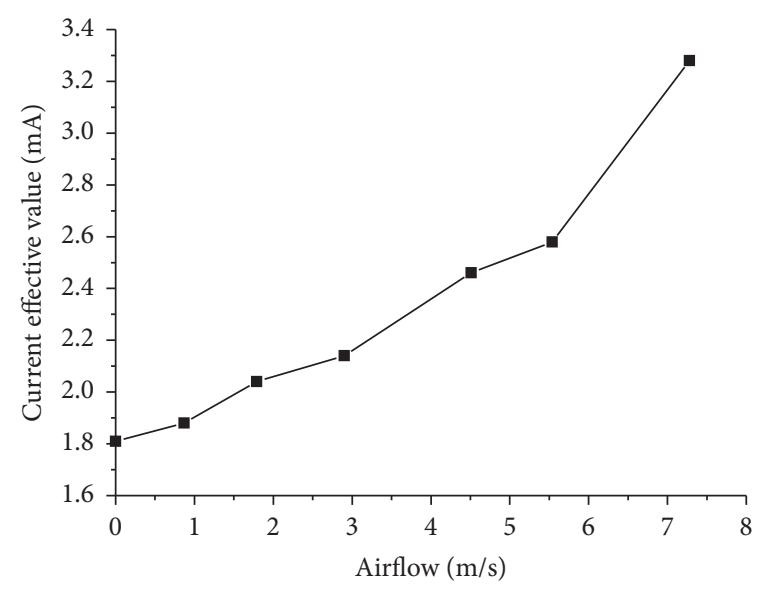

--- Current effective value

(c) Coupling resistance is $100 \Omega$

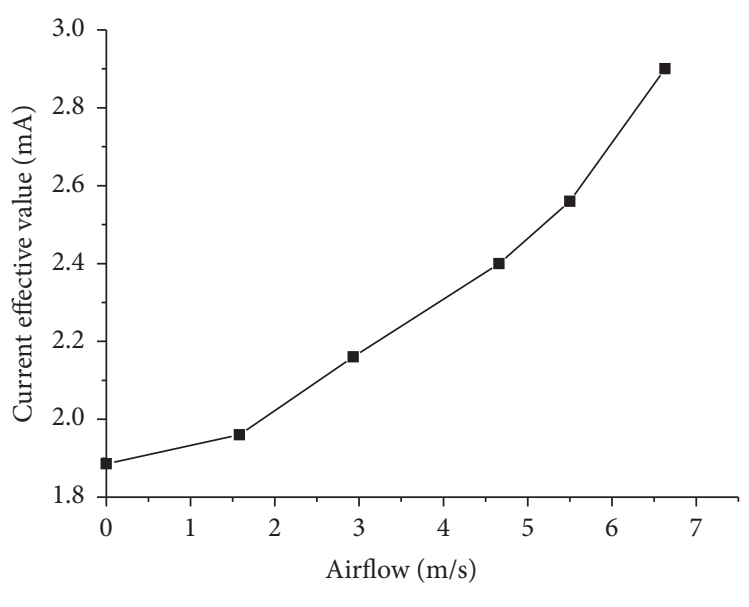

-- Current effective value

(b) Coupling resistance is $10 \Omega$

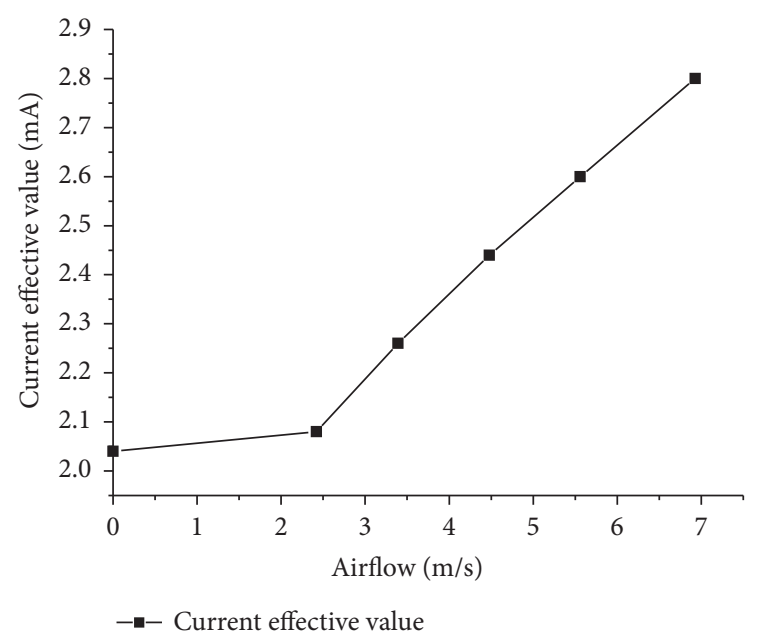

(d) Coupling resistance is $200 \Omega$

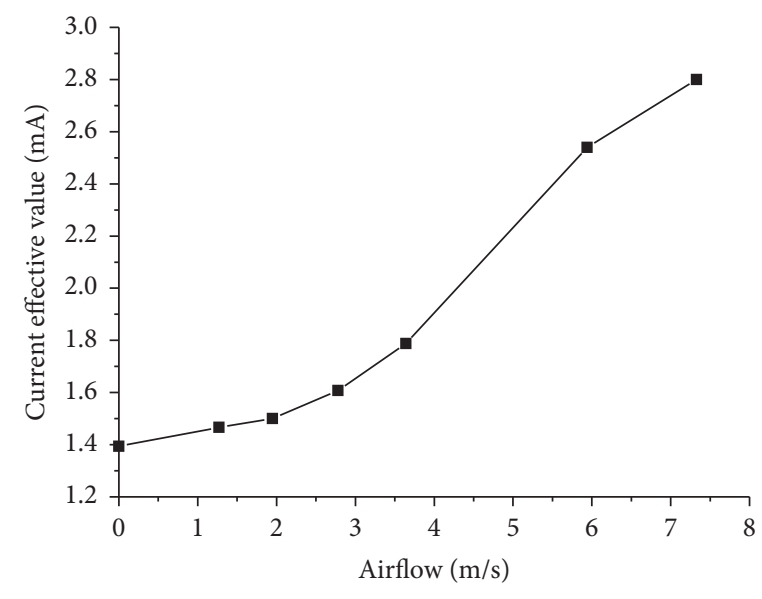

-- Current effective value

(e) Coupling resistance is $470 \Omega$

FIgURE 9: The relationship diagram of airflow velocity and the effective value of the current. 


\section{Acknowledgments}

This work is supported by the Natural Science Foundation of China (no. 51406083), Natural Science Foundation of Jiangsu Province (BK20140820), the Fundamental Research Funds for the Central Universities (no. NJ20160037), and Funding of Jiangsu Innovation Program for Graduate Education (No. SJZZ16_0055).

\section{References}

[1] Z. Zhou, J. Jones, A. M. Leung, W. Nie, and X. Wang, "A highlinearity DC planar Ionic anemometer," Flow Measurement and Instrumentation, vol. 45, pp. 118-125, 2015.

[2] J. Barat, "A high-resolution ionic anemometer for boundarylayer measurements," Journal of Applied Meteorology, vol. 21, no. 10, pp. 1480-1488, 1982.

[3] R. Klopfenstein, "Air velocity and flow measurement using a Pitot tube," ISA Transactions, vol. 37, no. 4, pp. 257-263, 1998.

[4] J. R. Burns, "Piezoelectric wind sensor," US, 1986.

[5] F. C. Lindvall, "A glow discharge anemometer," Transactions of the American Institute of Electrical Engineers, vol. 53, no. 7, pp. 1068-1073, 1934.

[6] W. Fucks, "Investigation of the operating properties of the leakage current anemometer," Technical Report Archive \& Image Library, 1947.

[7] R. F. Mettler, The anemometric application of an electrical glow discharge in transverse air streams [Ph.D. thesis], California Institute of Technology, 1949.

[8] F. D. Werner and R. L. Geronime, Applications of the Corona Discharge for Measurements of Density and Velocity Transients in Air Flow, 1953.

[9] C. Marshal, E. Matlis, T. Corke, and S. Gogineni, "Constant current plasma anemometer," in Proceedings of the 64th Annual Meeting of the APS Division of Fluid Dynamics (APS '11), Baltimore, Md, USA, 2011.

[10] C. Marshall, E. Matlis, T. Corke, and S. Gogineni, "Plasma anemometer measurements and optimization," in Proceedings of the 66th Annual Meeting of the APS Division of Fluid Dynamics, Pittsburgh, Pa, USA, November 2013.

[11] E. Matlis, P. Bowles, and T. Corke, "Plasma sensor suite," in Proceedings of the 61st Annual Meeting of the APS Division of Fluid Dynamics (APS '08), San Antonio, Tex, USA, 2008.

[12] E. Matlis, J. Cameron, S. Morris, and T. Corke, "A.C. plasma anemometer for axial compressor stall warning," in Proceedings of the 60th Annual Meeting of the Divison of Fluid Dynamics, November 2007.

[13] E. Matlis, T. Corke, J. Camerson, S. Morris, and P. Fay, "Highbandwidth plasma sensor suite for high-speed high-enthalpy measurements," in Proceedings of the 46th AIAA Aerospace Sciences Meeting and Exhibit, Reno, Nev, USA, January 2013.

[14] E. Matlis, T. Corke, and S. Gogineni, "Current control of an A.C. plasma anemometer for hypersonic flow measurements," in Proceedings of the 59th Annual Meeting of the APS Division of Fluid Dynamics, 2006.

[15] E. Matlis, T. Corke, and S. Gogineni, Plasma Anemometer and Method for Using Same, 2007.

[16] E. H. Matlis, T. C. Corket, and S. P. Gogineni, A.C. Plasma Anemometer for Hypersonic Mach Number Experiments, 2003.
[17] M. D. Yamanaka, H. Hirosawa, Y. Matsuzaka, and H. Tanaka, "“glow-discharge' ionic anemometer" Review of Scientific Instruments, vol. 56, no. 4, pp. 617-622, 1985.

[18] Y. Zhang, C. Ren, T. Ma et al., "RC-coupled atmospheric glow discharge in air," Plasma Science and Technology, vol. 8, no. 4, pp. 438-442, 2006.

[19] Y.-T. Zhang, Z.-F. Xu, T.-C. Ma, C.-S. Ren, B. Qi, and S.-Y. Miao, "AC pin-to-water electrode atmospheric pressure glow discharge in air," Journal of Dalian University of Technology, vol. 47, no. 5, pp. 625-628, 2007.

[20] Z. Wu and X. Zhang, Gas discharge, National Defence Industry Press, Beijing, China, 2012. 


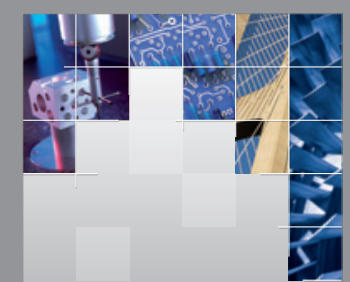

\section{Enfincering}
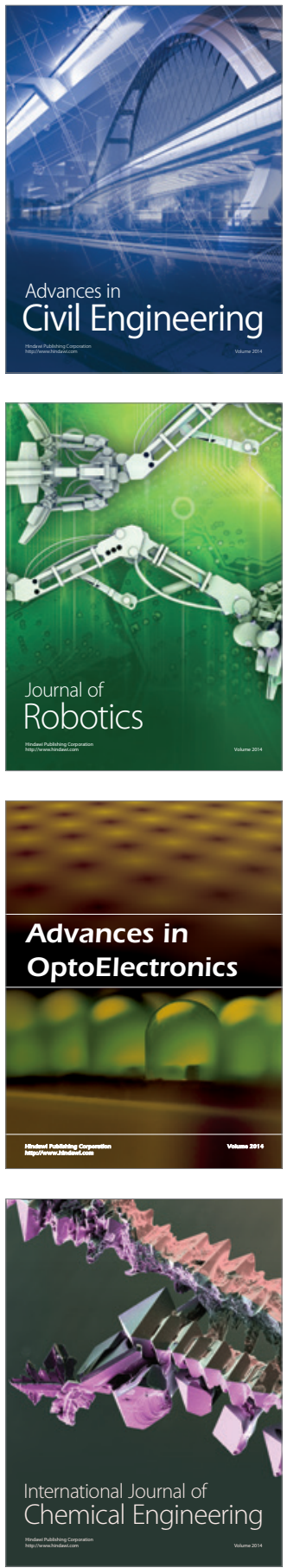

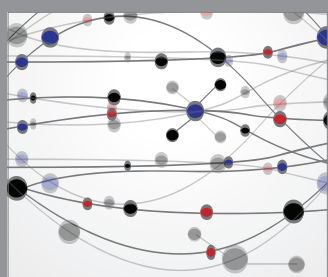

The Scientific World Journal

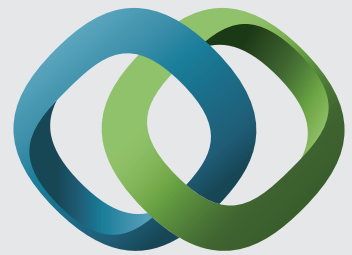

\section{Hindawi}

Submit your manuscripts at

https://www.hindawi.com
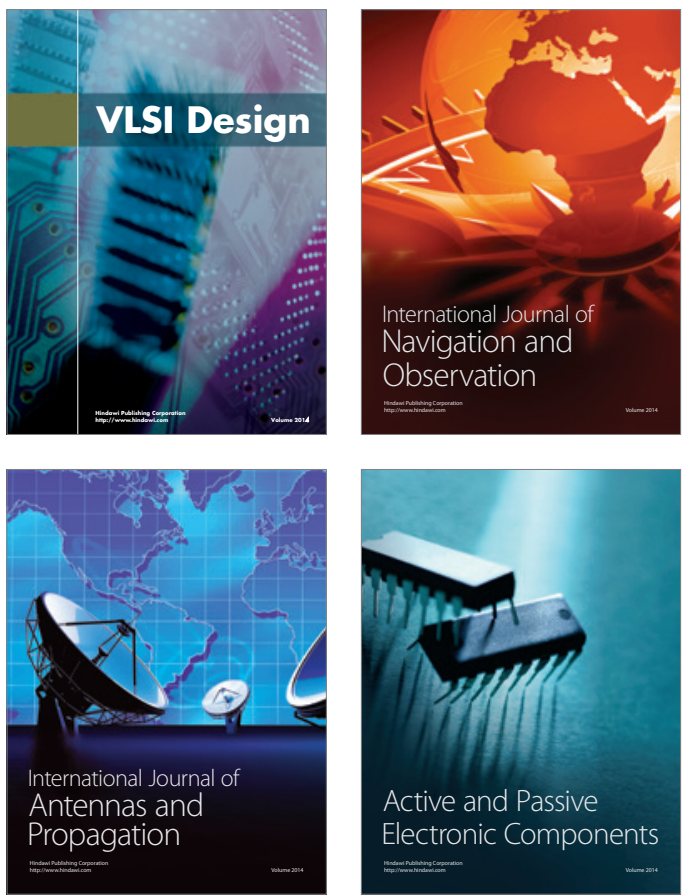
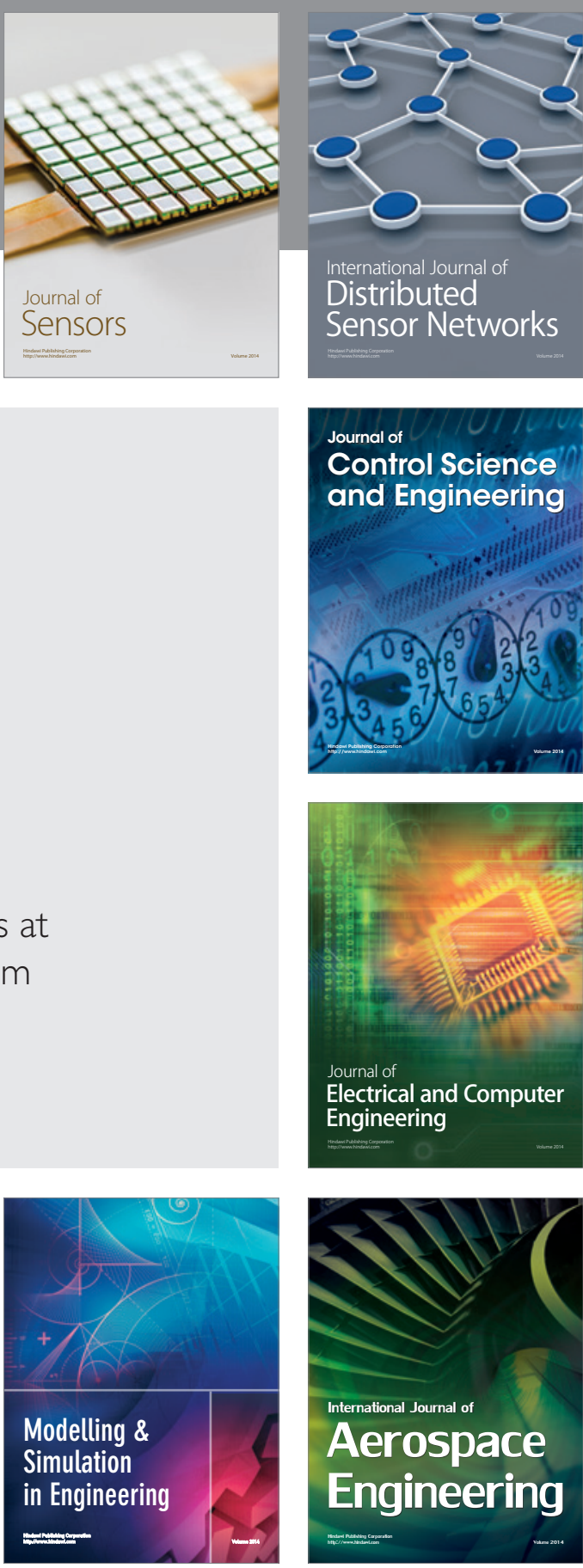

International Journal of

Distributed

Sensor Networks

$-$

Joumal of

Control Science

and Engineering
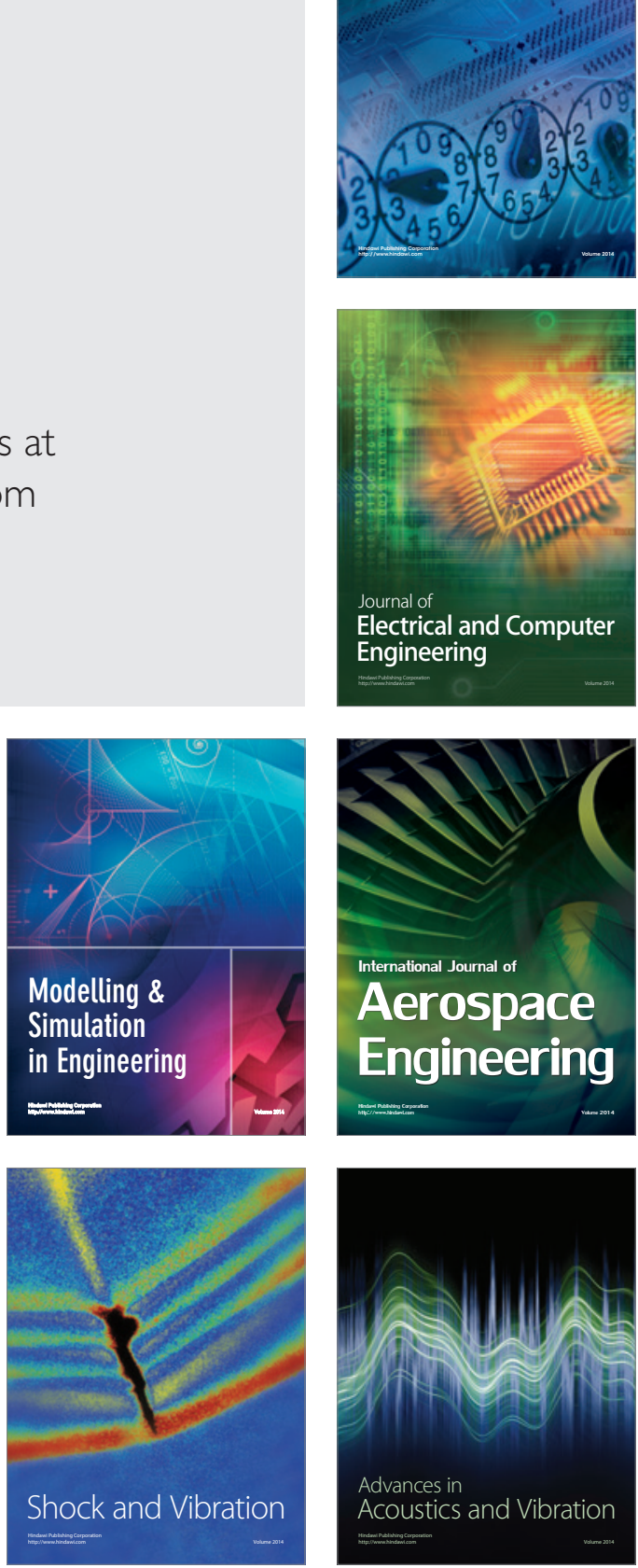